\title{
Investigation of the Mechanical Properties and Changes in Water Absorption Capacity of Natural Fiber Reinforced Polyoxymethylene
}

\author{
Yilmaz Kismet \\ Munzur University, Department of Mechanical Engineering, Tunceli, Turkey \\ E-mail: ykismet@munzur.edu.tr
}

\begin{abstract}
In this study, the changes in mechanical properties and changes in water absorption capacity of the polyoxymethylene (POM) with natural fiber reinforcement were investigated. Seaweed, rapeseed and acorn were used as natural fibers. Samples were prepared by mixing the powder of these fillers separately with the POM in 5\%,10\% and $20 \%$ by weight. The mixtures were first obtained mechanically in a mixer and then obtained to be homogeneous in extrusion. The homogenized mixtures were granulated in the granulator by cracking and then poured into the injection machine to produce test bars. The tensile, bending strengths and isod impact strengths and melt flow indexes of the samples were examined and the changes in these properties due to increasing filler amount and filler type were discussed showing by graphs. The change in the melt flow index was carried out separately for both mechanically formed mixtures and homogeneously obtained mixtures, and the effect of homogeneity on fluidity was determined. Besides the mechanical properties, the changes in the water absorption capacity of the samples were also examined.
\end{abstract}

Keywords: polyoxymethylene, natural fibers, mechanical properties, melt flow index

DOI: $10.7176 / J S T R / 5-12-26$

\section{Doğal Lif Takviyeli Polioksimetilenin Mekanik Özellikleri ve Su Emme Kapasitesindeki Değişimin İncelenmesi}

\begin{abstract}
Özet
$\mathrm{Bu}$ çalışmada, doğal lif takviyeli polioksimetilenin (POM) mekanik özelliklerindeki ve su emme kapasitesindeki değişimler incelendi. Doğal lif olarak deniz yosunu, kolza ve palamut tozu (vaks) kullanıldı. Bu dolgu maddelerinin tozları POM ile ayrı ayrı ağırlıkça \%5, \%10 ve \%20 olacak şekilde karıştırılarak numuneler hazırlandı. Karışımlar önce bir mikserde mekanik olarak daha sonrada ekstrüzyonda homojen olacak şekilde oluşturuldu. Homojen hale getirilen karışımlar kırıcıda kırılarak granül elde edildi ve daha sonra enjeksiyon makinasına dökülerek standart çekme numuneleri üretildi. Üretilen numunelerin çekme, eğilme gerilmeleri ve izod darbe dayanımları ile eriyik akış indeksleri incelendi ve artan dolgu miktarı ile dolgu çeşitine bağlı olarak bu özelliklerdeki değişimler grafiklerle gösterilerek tartışıldı. Eriyik akış indeksindeki değişim, ayrı ayrı hem mekanik olarak oluşturulan karışımlar için hem de homojen olarak elde edilen karışımlar için gerçekleştirildi ve homojenliğin akışkanlık üzerine olan etkisi tespit edildi. Mekanik özellikler dışında üretilen numunelerin su emme kapasitelerinde ki değişimlerde incelendi.
\end{abstract}

Anahtar Kelimeler: polioksimetilen, doğal dolgu, mekanik özellikler, eriyik akış indeksi 


\section{Giriş}

Endüstride birçok alanda kullanımı giderek artan polimerlerin başında termoplastik polimerler gelmektedir. Amorf ve kristal/yarı kristal olmak üzere molekül zincirlerinin dizilişine göre iki gruba ayrılan termoplastikler düşük maliyetli ve kolay bulunabildikleri için sıklıkla tercih edilmektedirler [13]. Ekstrüzyon ve plastik enjeksiyon başta olmak üzere farklı teknikler ile termoplastik polimerlerden üretim yapmak basit ve oldukça kolaydır. Termoplastiklerin en önemli grubunu polietilen ve polipropilenin yer aldığı poliolefinler oluşturmaktadır. Poliolefinler dışında polioksimetilen, polistiren, akrilonitril bütadiyen stiren, polikarbonat v.b yine endüstride sıklkla tercih edilen termoplastiklerdir [15].

Gelişen teknoloji ile insanların artan tüketim alışkanlıklarını giderebilmek için üretimde kullanılan termoplastiklere uygun alternatifler malzemeler geliştirilmiştir. Takviye ve dolgu bileşenlerinden oluşan bu alternatif malzemeler ile termoplastikler güçlendirilerek kompozit malzemeler elde edilmektedir. Endüstride ihtiyacın büyük bir kısmı bu şekilde geliştirilen kompozit malzemeler ile karşılanmaktadır. Otomobil endüstrisinde araçların iç kısımlarında kullanılan malzemelerin yaklaşık olarak \%50si polimer ve polimer matrisli malzemelerden olup yine bunların büyük bir çoğunluğu termoplastik matrisli kompozit malzemelerdir [5-8]. Matris malzeme ile fiziksel bir bağlanma mekanizması olușturan dolgu ve takviye maddeleri sentetik ya da doğal karakterde organik ve inorganik malzemelerdir [8-12]. Sentetik karakterde epoksi ve fenol reçineleri, boya atıkları, silikon türevleri v.b maddeler kullanılırken doğal olarak inorganik yapıda mermer tozu, bor türevleri, talk, kalyum, mika ve kalsit gibi maddeler kullanılmaktadır. Doğada sürekli yetişen yenilenebilir karakterde organik dolgu maddeleri de termoplastiklerde sıklıkla tercih edilmektedir. Bu tür dolgu maddelerin başında saman, jüt, sisal, kendir, kenevir, kenaf, deniz yosunu, kolza, pamuk v.b kullanılmaktadır [12-15].

Yarı kristal yapıda olan polioksimetilen önemli bir mühendislik termoplastiğidir. Homo-polimer ve kopolimer olarak elde edilebilen polioksimetilen den yüksek viskoziteli malzemler üretilirken genellikle ekstrüzyon tekniği kullanılmakta, düşük viskozite derecelerinde ise enjeksiyonla kalıplama tekniği kullanılarak üretim gerçekleştirilmektedir [16]. Ko-polimerler yüksek kristal yapıda, rijit, sert ve iyi nem dayanımına sahip iken homo-polimerler ssil dengesiz yapıya sahiptirler. Bu nedenle ko-polimerler homopolimerlere kıyasla daha iyi takviye kabul etmektedirler ve dolayısıyla ko-polimer yapıdaki polioksmetilenin mukavemetini arttırmak daha kolay olabilmektedir. Mekanik özellikleri iyi, kimyasallara karşı yüksek dirençli asetal copolymerler yüksek sıcaklıklarda kararlı ve alevlere karşı dayanıklıdırlar. Özellikle enjeksiyon ile kalıplamaya çok uygun olan POM'den dişli mekanizmaları, makaralar ve birçok inşaat ile mobilya sektörüne yönelik parça imal edilmektedir [16-17].

$\mathrm{Bu}$ çalışmada deniz yosunu, kolza ve palamut tozu (vaks) gibi yenilenebilir doğal dolgu maddeleri POM içerisinde takviye elemanı olarak kullanıldı. Bu şekilde doğal dolgu maddesinin çeşidi ve miktarına bağlı olarak POM'nin mekanik özellikleri ve morfolojik yapısı ile su emme kapasitesindeki değişimler incelendi.

\section{Materyal Metot}

\subsection{Materyal}

Çalışmalarda kullanılan matris malzeme polyoxymethylene (POM), ALCOM firmasına ait "POM770/1 WT1153-07LB" ürün numaralı acetal copolymer'dir. Kullanılan dolgu maddeleri ise Türkiye'nin farklı coğrafi bölgelerinde ki deniz kıyıları, ormanlık ve ekim alanlarından toplanarak kurutulmuş ve toz haline getirilmiş deniz yosunu, kolza ve palamut tozu (vaks) gibi sürekli yetişen, yenilenebilir bitki türleridir.

\subsection{Deneysel Çalışmalar}

Çalışmalarda öncelikle dolgu maddesi olarak kullanılan bitki çeşitleri kurutuldu ve ögütülerek toz haline getirildi. Bu şekilde hazırlanan dolgu maddeleri ağırlıkça $\% 5, \% 10$ ve $\% 20$ olacak şekilde ayrı ayrı matris malzeme olan POM ile mekanik olarak karıştırıldı. Hem akış analizi için hem de üretilecek numuneler için toplam 9 karışım hazırlandı. Her bir karışım 1,5 kg olacak şekilde ayarlandı.

\subsection{Eriyik Akış Indeksi (MFI)}

Her bir matris dolgu karışımından ortalama 8er gram malzeme eriyik akış indeks cihazına dökülerek akışkanlık analizi gerçekleştirildi. Analizler için Munzur Üniversitesi Makine Mühendisliği Polimer Teknolojileri laboratuvarında ki "JPT EQUIPMENT brand XRL 400A" model cihaz kullanıldı. Analizler standartlara uygun olacak şekilde POM için belirtilen $190{ }^{\circ} \mathrm{C}$ 'de ve $2,16 \mathrm{~kg}$ ağıllık etkisi altında test edildi. Matris dolgu karışımlarından önce saf POM analiz edildi ve akışkanlığı belirlendi. Daha sonra sırası ile $\% 5, \% 10$ ve $\% 20$ dolgu içeren (deniz yosunu, kolza ve palamut tozu) karışımlar test edildi ve dolgu çeşidi ile miktarına göre karışımların hem kütlesel (g/10min.) hem de hacimsel $\left(\mathrm{cm}^{3} / 10 \mathrm{~min}\right.$.) olarak eriyik akış indekslerinde meydana gelen değişimler grafiklerle gösterildi. $\mathrm{Bu}$ analiz sadece 
mekanik olarak hazırlanan matris dolgu karışımları için değil aynı zaman da ekstrüzyonda elde edilen homojen karışımlar içinde gerçekleştirildi ve homojenliğin akışkanlık üzerindeki etkisi belirlendi. Aynı zamanda numunelerin yoğunluklarında ki değişimlerde artal dlgu miktarı ve çeşidine bağlı olarak belirlendi.

\subsection{Numune Hazırlama ve Test Çubuklarının Üretimi}

Ayrı ayrı mekanik olarak hazırlanan 9 karışımın homojen hale gelmesi için üç bölge ısıtma ve bir kalıp 1sıtmaya sahip ekstrüder kullanıldı. Karışımların ekstrüderde ki çalışma sıcaklıkları ise POM'nin erime sıcaklığı ve eriyik akış analizi sonucunda elde edilen akışkanlık değerlerine göre Tablo 1'de belirtildiği gibi ayarlandı. Bu şekilde tek vida ekstrüder kullanılarak homojen hale getirilen karışımları $3 \mathrm{~mm}$ çapında silindirik kesite sahip ekstrüder çıkışında suya daldırılarak soğutuldu ve kırıcıdan geçirilerek 1 ila $3 \mathrm{~mm}$ büyüklügünde granül hale getrildi. Farklı dolgu ve karışım oranlarına sahip bu granüller daha sonra "EKIN100Ton" plastik enjeksiyon makinasına dökülerek standart çekme numuneleri üretildi.

\subsection{Mekanik Analizler}

Plastik enjeksiyon makinası ile üretilen matris/dolgu karışımlarına ait standart çekme numuneleri DIN EN ISO 527 (ASTM D 638) standartlarına uygun olacak şekilde "Shimadzu, model ag-x 10" cihazı kullanılarak gerçekleştirildi. Numuneler 2N'luk ön yükleme ile $50 \mathrm{~mm} / \mathrm{min}$. hızla çekmeye zorlandı. Numunelerin üç nokta eğilme dayanımları ise yine aynı cihaz kullanılarak DIN EN ISO 178 (ASTM D 790) standartlarına uygun olarak gerçekleştirildi. Maksimum $6 \mathrm{~mm}$ sehim olacak şekilde $10 \mathrm{~mm} / \mathrm{min}$. hızla numuneler düşey olarak yüklendi. Bir diğer mekanik analiz olan izod darbe dayanımı ise "CEASTFraction Plus" cihazı kullanılarak DIN ISO 180 (ASTM D 256, ASTM D 4508) standartlarına uygun olacak şekilde gerçekleştirildi. Standart çekme numuneleri 80x10x4 mm ebatlarında kesildi ve kesilen bu parçalar test edildi.

\subsection{Su Emme Kapasitesindeki Değişimler}

Matris/dolgu karışımlarından üretilmiş numuneler için su emme kapasitesinde ki değişimler DIN ISO 62-2 (ASTM D570) normlarına uygun olarak gerçekleştirildi. Hem saf hem de dolgu takviyeli numuneler 84 gün süresince oda sıcaklığında saf su içeren bir ortam içerisinde bekletildi. Numunelerin ağırlıkları saf su içersinde konulmadan belirlendi ve öncelikle 1. gün sonunda daha sonra 3. gün ve 7. Sonunda numuneler su içerisinde çıkarıldı ve yüzeyleri bir bez ile hafifçe silinerek ağırlıkları tespit edildi. Birinci hafta sonunda her 10 gün de bir numuneler su dan çıkarıldı ve ağırlıkları tespit edildi.

\section{Sonuçlar ve Tartışmalar}

\subsection{Melt Flow Index (MFI) and Density}

Mekanik olarak hazırlanmış matris/dolgu karışımlarına ait eriyik akış indeks değişimleri Şekil 1'de verilmiştir.

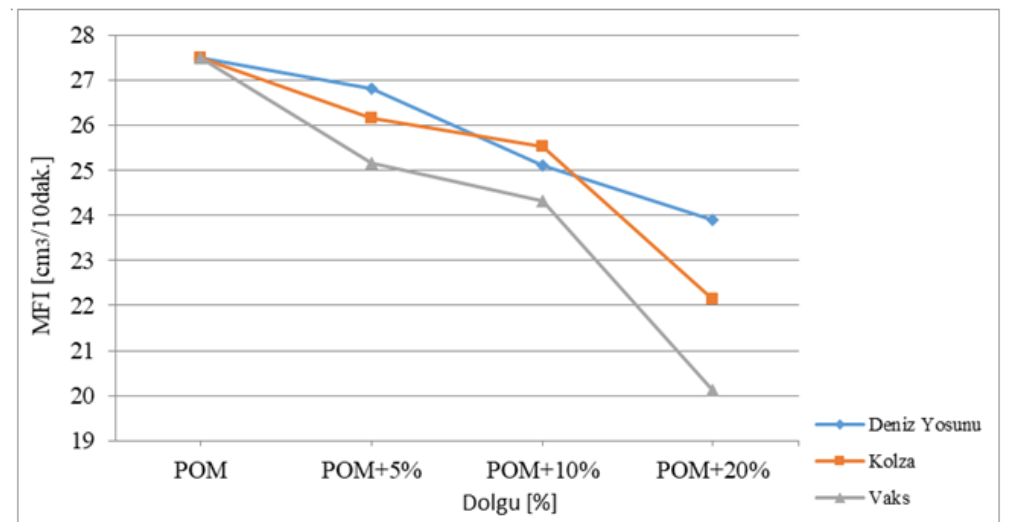

Şekil 1: Mekanik matris/dolgu karışımlarının eriyik akış indeks değişimi.

Yukarıda ki şekilde mekanik olarak hazırlanmış matris/dolgu karışımlarına ait hacimsel akış indeksi görünmekte olup, matris içerisinde artan dolgu miktarı ile POM'un akışkanlığı azalmıştır. Saf POM'nin hacimsel akış indeksi 27,5 cm3/10min. iken bu değer \%20 deniz yosunu içeren karışımda 23,8 cm3/10min. olarak tespit edilmiştir. \%20 kolza ve \%20 vaks içeren karışımlarda ise sırasıyla 22,2 cm3/10min ve 20,1 cm3/10min olarak ölçülmüştür. 


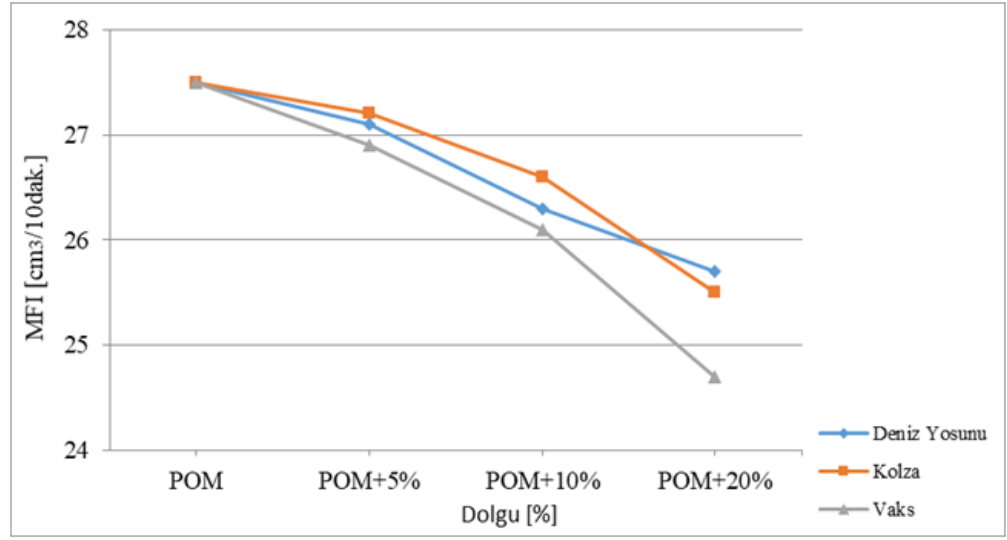

Şekil 2: Homojen matris/dolgu karışımlarının eriyik akış indeks değişimi.

Şekil 2'de homojen olarak hazırlanan matris/dolgu karışımlarının hacimsel eriyik akış indeksinde ki değişimin dolgu miktarı ve dolgu çeşidine bağlı olarak değişimi verilmiştir. Bu grafiğe göre, artan dolgu miktarı ile POM'un akışkanlığının azaldığı görülmektedir. \%20 dolgu içeren POM karışımlarının akışkanlıkları deniz yosunu içeren karışımlarda $25,7 \mathrm{~cm} 3 / 10 \mathrm{~min}$. kolza içeren karışımlarda 25,5 cm3/10min. ve vaks içeren karışımlarda $24,7 \mathrm{~cm} 3 / 10 \mathrm{~min}$. olarak tespit edilmiştir. Fakat bu durum mekanik karışımların akışkanlıkları ile mukayese edildiğinde yaklaşık olarak \%20-25 oranında bir iyileşme olduğu görülmektedir.

\section{2 Çekme Gerilmesi}

Dolgu miktarı ve çeşidine bağlı olarak POM'un çekme gerilmesinde ki değişim Şekil 3'de verilmiştir.

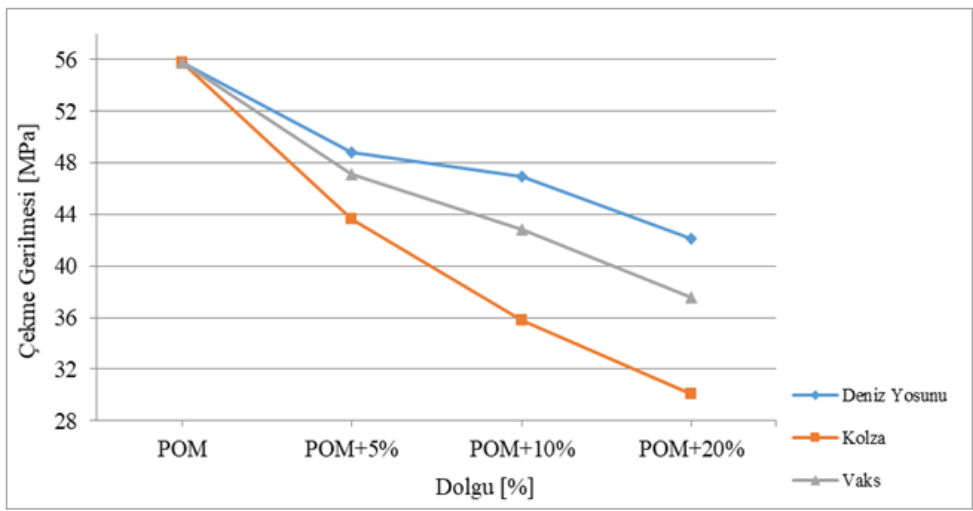

Şekil 3: Dolgu miktarı ve çeşidine bağlı olarak POM’un çekme gerilmesinde ki değişim.

Yukarıda ki grafiğe göre numunelerin çekme dayanımları artan dolgu miktarına bağlı olarak azalmıştır. $\mathrm{Bu}$ azalma özellikle dolgu maddesi olarak kolza içeren numunelerde radikal bir şekilde meydana gelmiştir. Saf POM numunelerinin çekme gerilmesi ortalama 5,8 MPa iken bu değer \%20 kolza içeren numunelerde 30,1 MPa olarak tespit edilmiş̧ir. Benzer şekilde deniz yosunu ve vaks içeren numunelerin de çekme dayanımları azalmış olup \%20 deniz yosunu içeren numunelerde ortalama 42,1 MPa ve \%20 vaks içeren numunelerde 37,6 MPa olarak belirlenmiştir. 


\section{$3.3 \ddot{U}$ ç Nokta Ĕ̈ilme Gerilmesi}

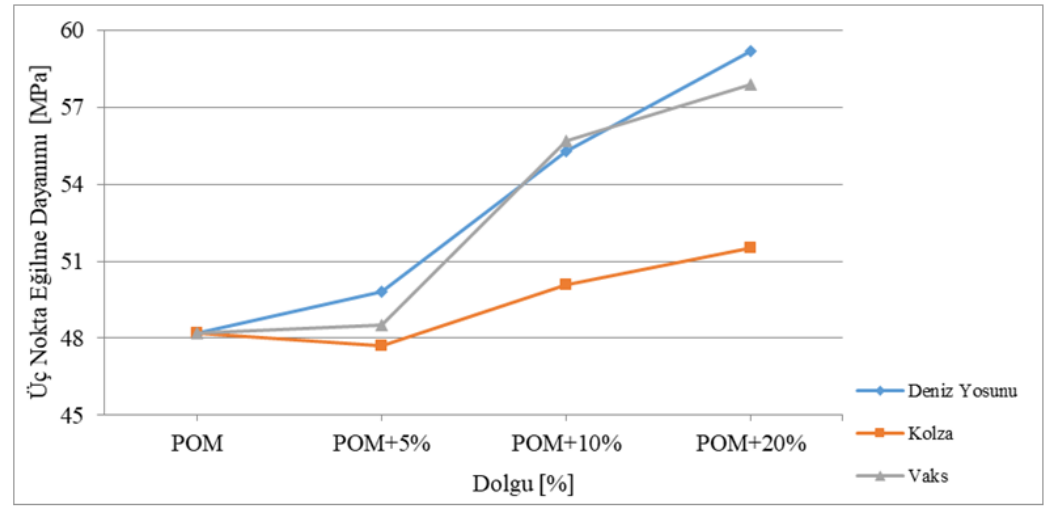

Şekil 4: Dolgu miktarı ve çeşidine bağlı olarak POM'un üç nokta eğilme gerilmesinde ki değişim.

Şekil 4'de dolgu miktarı ve çeşidine bağlı olarak POM'un üç nokta eğilme gerilmesinde ki değişim verilmiştir. Bu grafiğe göre matris içerisinde artan dolgu miktarına bağlı olarak numunelerin düşey yüklemelere karşı dayanımları artmıştır. Saf POM numunelerinin eğilme dayanımları 48,2 MPa iken bu değer \%20 deniz yosunu içeren numunelerde maksimum değere ulaşarak 59,2 MPa olmuştur. \%20 vaks içeren numunelerde ise 57,9 MPA ve \%20 kolza içeren numunelerde 51,5 MPa olarak tespit edilmiştir.

\subsection{Izod Darbe Dayanımı}

Şekil 5'de POM'nin izod darbe dayanımında ki değişimin dolgu miktarı ve çeşidine bağlı olarak değişimi verilmiştir.

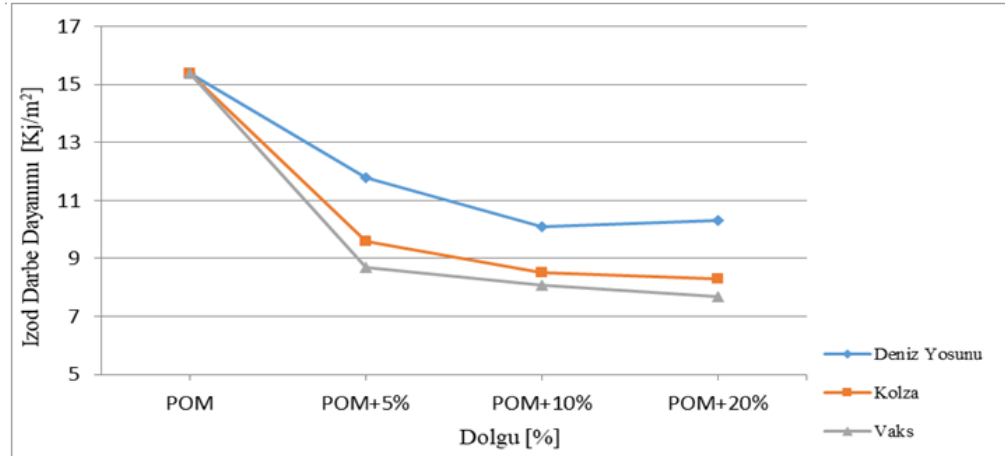

Şekil 5: Dolgu miktarı ve çeşidine bağlı olarak POM’un izod darbe dayanımında ki değişim.

Yukarıda ki grafiğe göre artan dolgu miktarına bağlı olarak numunelerin izod darbe dayanımlarının azaldığ1 görülmektedir. Özellikle $\% 5$ dolgu içeren numunelerde radikal bir azalma meydana gelmiştir. Saf POM'un darbe dayanımı 15,38 Kj/m² iken bu değer sırasıyla \%20 deniz yosunu, kolza ve vaks içeren numunelerde şu şekilde tespit edilmiştir; $10,3 \mathrm{Kj} / \mathrm{m}^{2}, 8,3 \mathrm{Kj} / \mathrm{m} 2$ ve $7,7 \mathrm{Kj} / \mathrm{m}^{2}$.

\subsection{Su Emme Kapasitesinde ki Değişim}

Tablo 1: Matris dolgu karışımına ait numunelerin su emme kapasitesinde ki değişim.

\begin{tabular}{|l|c|c|c|c|c|c|c|c|c|c|c|c|c|c|c|}
\hline GÜN & \multicolumn{3}{|c|}{7} & \multicolumn{3}{c|}{27} & \multicolumn{3}{c|}{47} & \multicolumn{3}{c|}{67} & \multicolumn{3}{c|}{84} \\
\hline Saf POM & \multicolumn{3}{|c|}{0,1} & \multicolumn{3}{c|}{0,4} & \multicolumn{3}{c|}{0,5} & \multicolumn{3}{c|}{0,6} & \multicolumn{3}{c|}{0,67} \\
& $\% 5$ & $\% 10$ & $\% 20$ & $\% 5$ & $\% 10$ & $\% 20$ & $\% 5$ & $\% 10$ & $\% 20$ & $\% 5$ & $\% 10$ & $\% 20$ & $\% 5$ & $\% 10$ & $\% 20$ \\
\hline & & & & & & & & & & & & & & & \\
D. Yosunu & 0,9 & 1,2 & 1,9 & 1,1 & 1,3 & 2,1 & 1,2 & 1,5 & 2,5 & 1,23 & 1,6 & 3,1 & 1,25 & 1,7 & 4,3 \\
\hline Kolza & 0,79 & 1,05 & 1,7 & 1,08 & 1,2 & 2,4 & 1,18 & 1,3 & 2,9 & 1,25 & 1,5 & 3,4 & 1,28 & 1,6 & 4,7 \\
\hline Vaks & 0,93 & 1,1 & 1,9 & 1,16 & 1,4 & 2,8 & 1,24 & 1,5 & 3,1 & 1,28 & 1,6 & 3,7 & 1,34 & 1,7 & 5,2 \\
\hline
\end{tabular}


Tablo 1'e bakıldığında artan gün sayısı ile numunelerin hepsinde su emme miktarlarının arttığ görülmüştür. Aynı zamanda karışım içerisinde artan dolgu miktarı ile de numunelerin su emme kapasitelerinin önemli ölçüde arttığı dikkat çekmektedir. Saf POM'un su emme kapasitesinde ki değişim 84 gün sonunda çok düşük olup $\% 0,67$ olarak tespit edilmiştir. Buna karşın $\% 20$ dolgu içeren numunelerin 84 gün sonunda su emme kapasiteleri ilk günkü ağırlığa kıyasla \%4,3 ila \%5,2 oranlarında artış göstermiştir.

\section{Sonuç ve Değerlendirme}

Gerçekleştirilen bu çalışma ile bir mühendislik termoplastiği olan POM'nin doğal dolgu takviyesi ile mekanik özelliklerinde ki ve su emme kapasitesinde ki değişimler tespit edildi. Elde edilen sonuçlar doğrultusunda;

POM içerisinde artan dolgu miktarına bağlı olarak karışımların akışkanlıklarının azaldığı fakat karışımların ekstrüzyon makinasından geçirilerek homojen hale getirilmeleri sonucunda akışkanlık değerlerinin mekanik karışımlara kıyasla \%20 civarında iyileştiği belirlenmiştir.

Farklı dolgu miktarı ve çeşidine bağlı olarak üretilen numunelerin tamamında eksenel yönde uygulanan kuvvet nedeniyle çekme dayanımının azaldığı görülmüştür. Bu azalmanın en önemli nedeni matris ile dolgu malzemesinin yeterince homojen karışmaması ve numune kesiti içerisinde hava boşluklarının oluşmasıdır. Numunelerin büyük bir çoğunluğunun çekme deneyi sonucunda kopan kesitlerinde hava boşlukları gözlemlenmiş ve numuneler zayıf olan bu kesitlerden kopmuşlardır. Bu durum üretim esnasında homojenliği arttırmak için çift vida esktrüder kullanılarak ya da matris ve dolgu malzemesinin bağlanma mekanizmasını iyileştirebilmek için Elastollan, Geniomer gibi farklı aditivler kullanılarak iyileştirilebilir. Bağlanma mekanizmasını iyileştirebilmek için aynı zamanda numuneler belirli süre ve dozda gama 1şımasına maruz bırakılabilir. Bu durumda da matris bozunmaya uğrayarak dolgu ile daha etkili bir bağlanma mekanizması oluşabilmektedir.

Çekme gerilmesine benzer bir şekilde numunelerin izod darbe dayanımının da dolgu çeşidinden bağımsız olarak artan dolgu miktarı ile azaldığı tespit edilmiştir. Yine bu durumda çekme gerilmesi için uygulanması önerilen teknikler ile iyileştirilebilir.

Çekme ve darbe dayanımlarının aksine numunelerin düşey yüklemelere karşı mukavemetlerinin karışım içerisinde artan dolgu miktarı ile artış gösterdiği tespit edilmiştir. Özellikle deniz yosunu ve vaks takviyeli numunelerde bu iyileşme $\% 20$ ila \%25 oranlarında gerçekleşmiş ve numunelerin eğilme dayanımları artmıştır.

Üretilen numuneler içerisinde kullanılan organik dolgu maddelerinin su emme kapasiteleri yüksek olduğu için artan dolgu miktarı ile numunelerin su emme oranları da artmıştır.

\section{Literatür}

[1] Kaiser,W. Polyolefine: Kunststoffchemie für Ingenieure, 4th ed.; Carl Hanser Verlag: München, Germany, 2016.

[2] Ehrenstein, W.G. Polymere Werkstoffe (Structur, Eigenschaften, Anwendungen), 3rd ed.; Carl Hanser Verlag:München, Germany, 1999.

[3] Ravve, A. Pronciples of Polymer Chemistry; Springer: New York, NY, USA, 2000.

[4] Gysau D. Füllstoffe. 2nd ed. Vincentz Network: Hannover, 2006.

[5] Zou P., Xiong H., Tang S., "Natural weathering of rape straw flour (RSF)/HDPE and nanoSiO2/RSF/HDPE composites", Carbohydrate Polymers, 73, 378-383, (2008)

[6] Etcheverry M and Barbosa S E., Glass Fiber Reinforced Polypropylene Mechanical Properties Enhancement by Adhesion Improvement, Materials, 5 (2012), pp. 1084-1113.

[7] Micusik M, Omastova M, Nogellova Z, Fedorko P, Olejinkova K, Trchova M, Chodak I, "Effect of crosslinking on the properties of composites based on LDPE and conducting organic filler", European Polymer Jaurnal, 42, 2379-2388, (2006).

[8] R. Nawang, I.D. Danjaji, U.S. Ishiaku, H. Ismail, Z.A. Mohd Ishak, 'Machanical proporties of sago starch-filled linear low density polyethylene (LLDPE) composites', Polymer Testing, 20, 167-172, (2001) 
[9] Kijenska M., Kowalska E., Palys B., Ryczkowski J., "Degradability of composites of low density polyethylene/polypropylene blends filler with rape straw", Polymer Degradation and Stability, 95, 536-542, (2010)

[10]Deng Y., Li N., Wang Y., Zhang Z., Dang Y., Liang J., "Enhanced dielectric properties of low density polyethylene with bismuth sulfide used as inorganic filler", Materials Letters, 64, 528530, (2010)

[11] Taurinoa, R., Sciancaleporeb, C., Collinia, C., Bondic, M., Bondiolia, F., Functionalization of PVC by chitosan addition: Compound stability and tensile properties. Composites Part B, 149 (2018), pp. 240-247.

[12]Zou P., Xiong H., Tang S., "Natural weathering of rape straw flour (RSF)/HDPE and nanoSiO2/RSF/HDPE composites", Carbohydrate Polymers, 73, 378-383, (2008)

[13] Juhasz A. J., Best S. M., Brooks R., Kawashita M., Miyata N., Kokubo T., Nakamura T., Bonfield W., "Mechanical properties of glass-ceramic A-W-polyethylene composites: effect of filler content and particle size", Biomaterials, 25, 949-955, (2004)

[14] Luo X., Li J., Feng J., Xie S., Lin X., "Evaluation of distillers grains as fillers for low density polyethylene: mechanical, reological and thermal characterization", Composites Science and Technology, 89, (2013)

[15] Naim, AA., Alnaim, N., Sobhy SI.,, Metwally SM., Effect of gamma irradiation on the mechanical properties of $\mathrm{PVC} / \mathrm{ZnO}$ polymer nanocomposite. Journal of Radiation Research and Applied Sciences, 10 (2017), pp. 165-171.

[16] S. Mathurosemontri, P. Auwongsuwan, S. Nagai, H. Hamada, Investigation of Friction and Wear Behavior of Polyoxymethylene/Poly(Lactic Acid) Blends Ener. Mater. 728 (2017) 229234.

[17]X. Guo, J. Zhang, J. Huang, Poly(lactic acid)/polyoxymethylene blends: morphology, crystallization, rheology, and thermal mechanical properties, Polymer 69 (2015) 103-109. 